\title{
Qafzeh 9 mandible (ca 90-100 kyrs BP, Israel) revisited: $\mu$-CT and 3D reveal new pathological conditions
}

D. Coutinho Nogueira ${ }^{\mathrm{a}, \mathrm{b}^{*}}$, O. Dutour ${ }^{\mathrm{a}, \mathrm{b}}$, H. Coqueugniot ${ }^{\mathrm{a}, \mathrm{b}}$, A.-m. Tillier ${ }^{\mathrm{b}}$

a - EPHE - PSL Research University, Paris - Chair of Biological Anthropology Paul Broca

b - UMR 5199 PACEA, CNRS - University of Bordeaux, Pessac

*Corresponding author: Dany Coutinho Nogueira, tel. + 335400025 48, E-mail address: dany.coutinho-nogueira@etu.ephe.psl.eu

Postal address (same for all authors): UMR 5199 PACEA, Université de Bordeaux, Bâtiment B8, Allée Geoffroy Saint Hilaire, CS 50023, 33615 Pessac cedex

Authors e-mails and phone:

Olivier Dutour: olivier.dutour@ephe.psl.eu - 0033540002552

Hélène Coqueugniot: helene.coqueugniot@u-bordeaux.fr - 0033540003743

Anne-marie Tillier: anne-marie.tillier@u-bordeaux.fr

Declarations of interest: none

Abbreviated title: New pathological conditions on Qafzeh 9 mandible 


\begin{abstract}
Objective: The aim of this paper is to provide new insights into growth patterns and health of Mousterian hunter-gatherers dated to ca. 90-100 kyrs B.P. from the Qafzeh site.

Material: An almost complete skeleton, including the mandible from the Qafzeh site (Qafzeh 9).
\end{abstract}

Methods: Micro-CT and medical imaging techniques are used to explore inaccessible inner structures and to assess the aetiology of identified lesion.

Results: Mandibular and dental conditions appear to be growth-related skeletal disorders.

Conclusion: To our knowledge, Qafzeh 9 offers the earliest evidence of associated mandibular and dental pathological conditions (i.e. non-ossifying fibroma of the mandible, pre-eruptive intracoronal resorption and osteochondritis dissecans of the temporomandibular joint) among early anatomically modern humans, and more generally among Middle Palaeolithic hominins in Southwestern Asia. The diagnoses can be added to other growth-related disorders of skulls previously documented from the Qafzeh site (Tillier 1999, Tillier et al. 2001), suggesting a quite high and exceptional incidence of these conditions compared to those of Palaeolithic populations.

Significance: Identification of pathological conditions in subadults from Eurasia dated to the Middle Palaeolithic is less documented than in adult skeletons. Hence, new results from immature fossil remains are particularly important to our understanding of the past.

Suggestions for further research: This research will be extended to the rest of the skeleton, then to all Qafzeh specimens in order to broaden our understanding of this anatomically modern group.

Keywords: anatomically modern humans, growth-related disorders, non-ossifying fibroma, osteochondritis dissecans, pre-eruptive intracoronal resorption 


\section{Introduction}

Qafzeh Cave is located on the Mount of Precipitation near the city of Nazareth (Lower Galilee). Excavations at the site were first conducted in the early 1930's by René Neuville and Moshé Stekelis and later, between 1965 and 1979, by a French-Israeli team lead by Bernard Vandermeersch (Neuville, 1951, Vandermeersch, 1981, 2007).

The hominin sample unearthed from Qafzeh Cave is represented by 8 partial skeletons and various isolated remains; all are identified as early anatomically modern humans (Vandermeersch, 1981; Tillier, 1999, 2014). The Mousterian units yielding most of the fossils (layers XVII to XXIII) were dated to circa 90-100 kyrs B.P. by electron spin resonance and thermoluminescence (Schwartcz et al., 1988; Valladas et al., 1988).

Within the hominin sample, Qafzeh 9 is of special interest. Discovered in August 1967 in layer XVII, and buried with a child, Qafzeh 10 (Vandermeersch, 1969), Qafzeh 9 is one of the most complete skeletons recovered from the site. Taphonomic processes, especially mechanical stress due to the weight of sediments, have affected the state of preservation of the bones (Vandermeersch, 1981).

The mandible of Qafzeh 9 exhibits bone fragmentation, distortion, and calcareous concretions. Despite this damage, the bone is nearly complete and all the permanent teeth are present (Fig 1). Taphonomic changes were initially described by Vandermeersch (1981); further analyses suggested the presence of skeletal and dental pathologies (Tillier et al., 2004; Arensburg et al., 2006). However, the aetiology of some of them is difficult to determine based solely on morphological observations.

Progress in medical imaging techniques has resulted in new opportunities for studying ancient human fossils (e.g. Uldin, 2018). Previous analyses of Levantine fossils using updated 3D methods have already resolved some anatomical issues and have provided access to previously inaccessible information (Coqueugniot et al., 2014; Amano et al., 2015; Schuh et al., 2017). For example, 3D reconstruction of the Amud I adult skull led to the re-evaluation of this highly fragmented skull and a virtual facial reconstruction (Amano et al., 2015). A 3D reconstruction of the Qafzeh 25 adult mandible, severely impacted by taphonomic processes, led to its first morphometric description (Schuh et al., 2017). Finally, a re-examination of the Qafzeh 11 skull has revealed that this immature individual had suffered from major cranio-encephalic trauma, probably affecting motricity and social communication (Coqueugniot et al., 2014). 
The purpose of this study is to analyse changes on the Qafzeh 9 mandible and assess their aetiology using 3D methods.

\section{Material and Methods}

Currently housed in the Department of Anatomy, Sackler School of Medicine, Tel Aviv University (Ramat Aviv, Israel), Qafzeh 9 represents the only specimen from the site attributed to the age class of 15 to 19 years (Vandermeersch, 1981; Tillier, 2006; Coutinho Nogueira et al., 2018). This individual was initially considered to be female (Vandermeersch, 1981), later confirmed (Brůžek and Vandermeersch, 1997), but Rak (1990) has suggested it is a male. The state of preservation of the pelvis and the young age at death might explain this contradictory sex determination.

The Qafzeh 9 mandible was covered by calcareous concretions at the time of its discovery. In addition to damage from taphonomic processes on the bone and teeth (fragmentation, distortion and missing elements) that were noted in the original description (Vandermeersch 1981), there are also a number of pathological changes (Tillier et al., 2004; Arensburg et al., 2006).

In order to further analyse and interpret these pathological changes, a micro-CT-scan of the Qafzeh 9 mandible (with an isometric voxel size of $80 \mu \mathrm{m}$ ) was performed. Digital images, and $3 \mathrm{D}$ reconstructions and measurements were analysed using TIVMI ${ }^{\circledR}$ software (Dutailly et al., 2009; Guyomarc'h et al., 2012) based on the HMH (Half Maximum Height) algorithm (Spoor et al., 1993).

Standard methods for differential diagnosis in paleopathology were applied to bone and dental changes (Ortner, 2003; Aufderheide and Rodríguez-Martín, 1998; Dutour, 2011). Taphonomic processes were classified using criteria defined by Weber and Bookstein (2011).

\section{Results}

\subsection{State of preservation}

According to Weber and Bookstein's (2011) criteria, the fossil has undergone several types of disturbance: fragmentation (type 1) and distortion (type 3), especially on the anterior symphyseal part of the mandible; missing parts (type 2) on the lingual aspect of the right body, the left condylar process, and the roots of the first and third right molars; and calcareous concretion covering the bone (type 4).

\subsection{Bone Modifications}


Two defects were identified on the surface of the mandible: one on the right condylar process and the other in the left mandibular angle.

The articular surface of the right condylar process presents a circular and superficial defect on the medial part (maximum Ø: $2.33 \mathrm{~mm}$; Fig. 2). Based upon morphological observation in a previous study (Arensburg et al., 2006), this defect was interpreted as avascular osteonecrosis. Micro-CT slices showed that beneath the defect sclerotic trabecular bone containing vascular canals is present (Fig. 3). This excludes taphonomic processes as the origin of this defect. Moreover, no anatomical variation of similar structure has been described in this condylar region (Le Double, 1906; Hauser and De Stefano, 1989).

Analysis of micro-CT slices and 3D reconstructions from an antero-superior orientation reveal the presence of a defect on the left gonial angle. This defect has a tubular shape (L: $8.57 \mathrm{~mm}$; Ø: $1.66 \mathrm{~mm}$ ) and affects only the cortical bone on the lingual side (Fig. 4A). The defect closes abruptly at its superior aspect with a slightly domed shape (Fig. 4B). This region of the mandible is affected by taphonomic damage and a small section of the gonial angle is missing. Consequently, it is likely that this defect was longer and extended to the outside of the bone, as it does not taper near the damaged end. Slight deformation of the bone is noted on the lingual surface. Based upon the defect shape, the slight deformation of the bone surface (Fig. 4A), and the fact that only the cortical bone is affected, a taphonomic process as the origin of this change, including the action of insects (termites or Dermestidae; Huchet et al., 2011; 2013), can be excluded. Further, around the defect, the cortical bone is denser. No normal anatomical variation has been described in this region of the mandible (Le Double, 1906; Hauser and De Stefano, 1989). However, the presence of a beam hardening effect that creates a blur in this region renders the need for a cautious conclusion (Fig. 4C).

\subsection{Dental Changes}

A number of mandibular teeth exhibit enamel or dentin defects, either on the surface or internally. Three main lesions are observed in the enamel of the mandibular molars. Two of them are located on the first and third right molars, both on the interproximal surface in contact with the second molar, but without affecting it (Fig. 5). The two defects are similar in shape (semi-circular canals) and dimension. The edges are sharp and the defects have a smooth surface. The enamel is affected over its entire thickness, but the dentin appears to be intact. In addition, the two molars have lost most of their roots due to taphonomic processes. They are, therefore, the least well-preserved teeth in the entire sequence. 
Micro-CT slices reveal fracture lines in the dental enamel that pass through the defects. They also confirm that the dentin remains intact or is only slightly impacted in both teeth (Fig. 6). The edges of these defects are straight and form right angles. The morphology of the defects, the fact that they do not affect the dentin, and the state of preservation of the teeth argue for taphonomic damage.

The first left molar presents an enamel defect on the mesiolingual side of the tooth (Fig. 7). Unlike the two previous defects, the edges of this feature are not sharp and the surface appears granular. The dentin appears to be only superficially affected.

The CT slices confirm all the morphologic observations (Fig. 8). No fractures are present in this region of the molar. Thus, it seems that the cause of this defect is lysis of the enamel and the dentin. It is difficult from these observations to determine if this damage occurred ante or post mortem. However, its single location suggests a carious lesion.

The second right molar presents a radiolucency in the dentin immediately below the dentinenamel junction. The 3D reconstruction of this defect (L: $2.56 \mathrm{~mm} ; 1: 1.977 \mathrm{~mm} ; \mathrm{H}: 1.01 \mathrm{~mm}$ ) reveals that its shape is similar to the dentin-enamel junction but it has lateral and inferior outgrowths; the lesion is symmetrical in shape. Two channels may link the defect to the occlusal surface. However, in this area, there is a beam hardening effect likely due to the resin (from restoration) creating a blurred region around the tooth and obscuring observation of small features (Fig 9).

\section{Discussion and conclusions}

With regard to the identification of bone modifications and their possible aetiology, different interpretations are offered.

The clinical literature (Sarrat et al., 1999) describes two disorders possibly responsible for the type of condylar defect identified: avascular (aseptic) osteonecrosis (AVN) and osteochondritis dissecans (OD). Although resulting in similar consequences to the condyle surface, these two disorders differ in their pathogeneses. AVN results from a lack of blood supply, leading to osteonecrosis. Bone damage is progressive and significant in size (Sarrat et al., 1999). OD results from localised cartilage loss often induced by trauma (e.g. trans-chondral fracture). As the bone is no longer protected, the exposed area erodes and the underlying region is remodelled in response to the stress (Schellhas et al., 1989; Sarrat et al., 1999). According to Schellhas et al. (1989), OD is a common disorder but is rarely identified clinically. It can cause pain and 
joint disability; dental occlusal issues and temporomandibular joint (TMJ) instability are frequently associated with OD. Ollat et al. (2008) believes that adult cases of OD result from unhealed cases of immature trauma. OD appears more frequently in adolescence than in childhood (more than two times greater). The sex ratio is $2: 1$, with males more often affected than females (Orhan et al., 2006). These data must be carefully evaluated: reported frequency rates include all affected regions of the body, with lesions on the lower limbs (knee and ankle) and elbow representing the majority of cases, and are often linked in modern populations to sports activities (Maillard et al., 2018). Moreover, in the study by Schellhas et al. (1989), 35 of the 40 cases with OD or AVN of the TMJ were females. Given the small size of the defect and the presence of vascular canals in the sclerotic area, it is reasonable to propose that Qafzeh 9 was suffering from osteochondritis dissecans of the right temporomandibular joint and not AVN.

Two primary hypotheses can be proposed for the gonial angle defect: a Stafne defect and a nonossifying fibroma of the mandible. A Stafne bone cavity (SBC) is a benign lesion appearing on the lingual side of the mandible near the gonial angle (Stafne, 1942). It is rarely reported (0.10 to $0.48 \%$ ), probably because it is asymptomatic and thus fortuitously discovered. Therefore, its frequency is likely underestimated. Its aetiology is still debated, but could result from pressure on the bone induced by salivary glands (More et al., 2015; Curien et al., 2016). However, the observed lesion on Qafzeh 9 is not located in an anatomical position near to the salivary gland; it is a defect within the cortical bone itself. Further, the shape of the SBC (circular or oval) and the fact that it reportedly affects men over 40 years old, contradicts this diagnosis.

Non-ossifying fibroma (NOF) or fibrous cortical defect (FCD) are benign tumours observed during skeletal development, affecting long bones and all the regions of the mandible. Mandibular involvement is more frequent in older individuals, but NOF on long bones has a reported mean age of 18.9 yrs and impacts females more than males (sex ratio 1:2.5) (Bowers et al. 2013). Since 1964, only twenty-one cases have been described in the clinical literature (Merhi Turki, 2014). Because NOF is asymptomatic and fortuitously discovered in clinical settings, its frequency is likely underestimated (Bowers et al. 2013). In addition, only unusual cases (large size resulting in tooth loss or fracture) are published, which certainly plays a role in the low recorded frequency of this type of lesion. On long bones, proposed frequencies range from 30 to $40 \%$ for children with normal growth and development (Huvos, 1979; Herget et al., 2016). All the studies indicate that the mandibular lesions are much rarer but there are no clear estimates of the frequency (Bailey et al., 2001; Bowers et al. 2013; Merhi Turki, 2014). 
Among modern populations (Merhi Turki, 2014), cases of mandibular NOF are diverse in shape and dimension. A lesion with similar shape and dimension to that of Qafzeh 9 was described on an adolescent femur from late antiquity (Dutour et al., 1989). Because of the age of Qafzeh 9 (between 15 and 19 yrs old) and the similarity of the shapes of the Qafzeh lesion and that reported by Dutour et al., a diagnosis of mandibular non-ossifying fibroma/fibrous cortical defect is proposed.

Taphonomic alteration or a cariogenic lesion cannot be excluded as causes of the dental changes noted on the second molar and the possible existence of channels crossing the enamel. However, the defect's location near the dentin-enamel junction, and the slight degree of enamel alteration support a diagnosis of a pre-eruptive intra-coronal resorption (PEIR) (Colin, 2015). This condition occurs during tooth eruption and is observed on erupted teeth. Clinical literature indicates that these lesions are usually progressive (Kjær et al., 2012; Colin, 2015), but occasionally non-progressive (Moskovitz and Holan, 2004). In rare instances, PEIR can cause pain when it reaches the pulp chamber (Klambani et al., 2005). However, the principal consequence of this lesion is weakening of enamel and dentin that can result in further tooth decay or fracture. This aetiology is subject to debate, but for a few authors, resorption of the dentin results from invagination of odontoblasts through ducts in the enamel (Savage et al. 1998; Klambani et al. 2005; Colin 2015).

In sum, there are at least three age-related disorders on the Qafzeh 9 mandible: a non-ossifying fibroma, osteochondritis dissecans and pre-eruptive intracoronal resorption. These observations add to the dental anomalies previously recorded on the Qafzeh 9 young individual. Indeed, the second left upper incisor is lingually positioned on Qafzeh 9 (Fig. 10; Vandermeersch, 1981; Tillier, 2007), impacting normal occlusion (anterior cross bite). The presence of a wear facet on the buccal surface supports this assertion and excludes post mortem change of the tooth position (Tillier 2007). According to Sarig et al. (2013), the misalignment of the dentition has caused "mesialization of the teeth, midline deviation, rotations and the aggravation of crowding". This dental condition of Qafzeh 9 can be linked to the diagnosis of osteochondritis dissecans of the condylar process. Indeed, malocclusion and trauma have been noted as responsible for OD (Schellhas et al., 1989; Sarrat et al., 1999). Thus, it appears that the defect on the mandibular condyle was caused by recurrent (micro) trauma to TMJ due to malocclusion.

It is difficult to determine the exact moment when each of these disorders appeared during Qafzeh 9's development. However, the pre-eruptive intracoronal resorption could appear only between the beginning of dentin formation and tooth eruption of the second molar, which means 
between 4 and 11 years (Moorrees et al., 1963). PEIR can continue throughout life, causing caries and/or fractures in the enamel. The small size of Qafzeh 9 PEIR might be associated with his/her young age.

OD and NOF of the mandible commonly appear during adolescence and sometimes persist into adulthood. If OD was linked with malocclusion and the retroalveolar position of the second upper incisor, its development would have occurred after the complete eruption of the tooth, which means at around 9 years old. The mean age for NOF appearance is 18.9 years, and as Qafzeh 9 was certainly younger (Coutinho Nogueira et al. 2018), the lesion had probably recently appeared and was still progressing. In the case of Qafzeh 9, PEIR likely appeared during childhood, followed by the early adolescence occurrence of OD, while NOF developed shortly before the individual's death.

Cases of tooth misalignment and carious lesions seen in Qafzeh 9 are rarely described in Middle Palaeolithic Eurasian hominins. Yet, they are not exceptional within the Qafzeh sample (Tillier, 1999, Tillier et al., 2004, Tillier 2007, Trinkaus and Pinilla 2009, Sarig et al., 2013, Schuh et al., 2017). Qafzeh 9 and 10 show a retroalveolar position of $\mathrm{LI}^{2}$, while tooth rotation affects two children (Qafzeh 11, 15) and one adult (Qafzeh 25). Carious lesions are present on two non-adults (Qafzeh 4 and 9) and two adults (Qafzeh 3 and 7). Qafzeh 3 stands out because of the high number $(n=3)$ of carious lesions that were detected (Trinkaus and Pinilla, 2009). Additional Middle Palaeolithic Levantine cases come from the Skhul and Kebara sites (Skhul II and Kebara 27, Sognnaes, 1956; Tillier et al., 1995, 2004). According to Trinkaus and Pinilla (2009), dental caries described exclusively on fossils around the Mediterranean basin suggest the presence of food richer in carbohydrates than in the rest of Eurasia. It can be also argued that the prevalence of tooth loss among European Neanderthals, as well as the lack of systematic investigations into dental pathology, require further investigation. Research into individual differences in immunological defence or response might also prove promising.

In this study, microtomodensitometry has been extremely helpful in identifying developmental disorders and oral health conditions of Qafzeh 9. To our knowledge, Qafzeh 9 offers the earliest evidence of associated mandibular and dental pathological conditions (i.e. non-ossifying fibroma of the mandible, pre-eruptive intracoronal resorption and osteochondritis dissecans of the temporomandibular joint) among early anatomically modern humans and more generally among Middle Palaeolithic hominins in Southwestern Asia. The diagnosis provided here can be added to other non-traumatic disorders of skull growth previously reported from the Qafzeh 
site (Tillier 1999, Tillier et al. 2001), suggesting a quite high and exceptional incidence of these conditions compared to those of Palaeolithic populations.

\section{Acknowledgments}

We are grateful to Prof. Israel Hershkovitz, curator of the anthropological collection of the Sackler School of Medicine, for access to the original fossil and the 3D images, to Julia Abramov, collection manager, for the reception and logistics support at the University of Tel Aviv. The authors are also thankful to Bernard Vandermeersch, Baruch Arensburg and Ofer Bar Yosef for their permission to study the remains found at Qafzeh. There is no permit number.

We would like to thank Prof. Alan E. Mann from Princeton University and Prof. Anne L. Grauer from Loyola University Chicago and editor-in-chief of the IJPP, for the English editing and their suggestions. We also thank the anonymous reviewer and the associate editor for their comments and recommendations to improve the quality of the manuscript.

This research was supported by the Irene Levi Sala Care Archaeological Foundation.

The research was conducted under the project LaScArBx (Programme Investissements d'Avenir, ANR-10-LABX-52).

Declarations of interest: none

\section{Captions}

Figure 1. Mandible of Qafzeh 9 (CAsher Pinchasov).

Figure 2. Defect on the right mandibular condyle.

Figure 3. MicroCT slice of the mandibular condyle.

Figure 4. Defect on the left gonial angle: A) MicroCT slice of the left side of the mandible; B) $3 \mathrm{D}$ reconstruction of the defect; C) micro-CT slice showing the defect, arrows point to areas of bone density; D) 3D reconstruction of the left side of the mandibular and defect; E) radiograph of the left side of the mandible.

Figure 5. Occlusal view of the right molars with the enamel defects on the $\mathrm{RM}_{1}$ and $\mathrm{RM}_{3}$, arrows point the two defects. 
Figure 6. Micro-CT slice of the right molars, arrows point the fractures visible in $\mathrm{RM}_{3}$.

Figure 7. Enamel defect of $\mathrm{LM}_{1}$.

Figure 8. Micro-CT slice of $\mathrm{LM}_{1}$.

Figure 9. Defect on the $\mathrm{RM}_{2}$ : A) micro-CT slice of the molar, arrow points the defect on the dentine; B) 3D reconstruction of the molar and the defect; C) 3D reconstruction of the defect. Figure 10. Qafzeh 9 maxillary dental arch (CAsher Pinchasov).

\section{Bibliography}

Arensburg, B., Duday, H., Tillier, A.-m., 2006. Approche paléopathologique de la sépulture double de Qafzeh (Israël). Communication au colloque du Groupement des Paleopathologistes de Langue Française, Lille, 25-26 mars 2006

Aufderheide, A.C., Rodríguez-Martín, C., 1998. The Cambridge Encyclopedia of Human Paleopathology Cambridge University Press, Cambridge, 498p.

Amano, H., Kikuchi, T., Morita, Y., Kondo, O., Suzuki, H., Ponce de Leon, M.S., Zollikofer ,C.P.E., Bastir, M., Stringer, C., Ogihara, N., 2015. Virtual Reconstruction of the Neanderthal Amud 1 cranium. American Journal of Physical Anthropology 158, 185-197. $\underline{\text { https://doi.org/10.1002/ajpa.22777 }}$

Bailey J.S., Nikitakis N.G., Lopes M., Ord R.A. (2001) Non-ossifying fibroma of the mandible in a 6-year-old girl: a case report and review of the literature. J Oral Maxillofac Surg. 59: 815818. doi: 10.1053/joms.2001.24303

Bowers, L.M., Cohen, D.M., Bhattacharyya I., Pettigrew Jr J.C., Stavropoulos MF., 2013. The Non-ossifying Fibroma: A Case Report and Review of the Literature, Head and Neck Pathology 7, 203-210 https://doi.org/10.1007/s12105-012-0399-7

Brůžek, J., Vandermeersch, B., 1997. Reassessment of the sex of the Qafzeh 9 individual based on multivariate statistical analysis. American Journal of Physical Anthropology, Supplement, 24,84

Colin, H. 2015. Les défauts dentinaires pré-éruptifs, Thesis, University of Nantes, France 92p. 
Coqueugniot, H., Dutour, O., Arensburg, B., Duday, H., Vandermeersch, B., Tillier A.-m. 2014. Earliest Cranio-Encephalic Trauma from the Levantine Middle Palaeolithic: 3D Reappraisal of the Qafzeh 11 Skull, Consequences of Pediatric Brain Damage on Individual Life Condition and Social Care. PLoS ONE, 9(7), e102822. doi:10.1371/journal.pone.0102822.

Coutinho Nogueira, D., Coqueugniot, H., Tillier, A.-m., 2018. La microtomodensitométrie, nouvel outil d'analyse de fossiles humains anciens : l'exemple de Qafzeh 9. Supplément des Bulletins et Mémoires de la Société d'Anthropologie de Paris 30, S14

Curien, R., Bally, J., Sourdot, A., Bravetti, P., 2016. La lacune de Stafne : à propos d'un cas. Actualités Odonto-Stomatologiques 277, 5 doi.org/10.1051/aos/2016045

Dutailly, B., Coqueugniot, H., Desbarats, P., Gueorguieva, S., Synave, R., 2009. 3D surface reconstruction using HMH algorithm. Proceedings of IEEE International Conference on Image Processing 2505-2508

Dutour, O., Zakarian, H., Sarrat, P., Williams, J., Duval, F., Bérato, J. 1989. Lacune corticale métaphysaire chez un adolescent du VIIIe siècle : cas paléontologique. Journal de Radiologie, $70, n^{\circ} 2: 139-140$

Dutour, O., 2011. La paléopathologie, Éditions du cths, Paris, 170p

Guyomarc'h, P., Santos, F., Dutailly, B., Desbarats, P., Bou, C., Coqueugniot, H., 2012. Threedimensional computer-assisted craniometrics: A comparison of the uncertainty in measurement induced by surface reconstruction performed by two computer programs, Forensic Science International, 219, Issues 1-3, 221-227, doi.org/10.1016/j.forsciint.2012.01.008

Hauser, G., De Stefano, G.F., 1989. Epigenetic Variants of the Human Skull. Stuttgart, Schweizerbart'sche Verlagsbuchhandlung. 301p.

Herget G.W., Mauer D., Krauss T., El Tayeh A., Uhl M., Sudkamp NP., Hauschild O. (2016) Non-ossifying fibroma: natural history with an emphasis on a stage-related growth, fracture risk and the need for follow-up. BMC Musculoskelet Disord. 17:147. doi: 10.1186/s12891-016$1004-0$

Huchet, J.B., Deverly, D., Gutierrez, B., Chauchat, C., 2011. Taphonomic evidence of a human skeleton gnawed by termites in a Moche-civilisation grave at Huaca de la Luna, Peru. International Journal of Osteoarchaeology, 21, 92-102. doi:10.1002/oa.1110 
Huchet, J.B., Le Mort, F., Rabinovich, R., Blau, S., Coqueugniot, H., Arensburg, B. 2013. Identification of dermestic pupal chambers on Southern Levant human bones : inference for reconstruction of Middle Bronze Age mortuary practices. Journal of Archaeological Science. 40, 3793-3803. https://doi.org/10.1016/j.jas.2013.04.025

Huvos AG. (1979) Nonossifying Fibroma. In: Bone tumors: diagnosis, treatment, and prognosis. Philadelphia, PA: W. B. Saunders; 297-306

Kjær, I., Steiniche, K., Kortegaard, U., Pallisgaard, C., Bille, M.L.B., Seirup, T., Skjødt, O., Larsen, H.J., 2012. Preeruptive intracoronal resorption observed in 13 patients. American Journal of Orthodontics and Dentofacial Orthopedics. 142, 129-132.

Klambani, M., Lussi, A., Ruf, S., 2005. Radiolucent lesion of an unerupted mandibular molar American Journal of Orthodontics and Dentofacial Orthopedics, 127, 67-71

Le Double, A.F. 1906. Traité des variations des os de la face de l'homme et de leur signification au point de vue de l'anthropologie zoologique. Vigot Frères Ed., Paris. 471p.

Maillard, B., Delvaux, F., Croisier, J.L., Desprechins, B., Ferrara, M.A., Simoni, P., Kaux, J.F. 2018. L’ostéochondrite disséquante. Journal de Traumatologie du Sport 35, 25-39.

Mehri Turki, I. 2014. Le fibrome non ossifiant mandibulaire : différences par rapport aux localisations orthopédiques et implications thérapeutiques. Médecine Buccale Chirurgie Buccale. 20, 185-188.

Moorrees, C.F.A., Fanning, E.A., Hunt, E.E. 1963. Age Variation of Formation Stages for Ten Permanent Teeth. Journal of Dental Research. 42, 1490-1502.

More, C.B., Das, S., Gupta, S., Patel, P., Saha, N. 2015. Stafne’s Bone Cavity: A Diagnostic Challenge. Journal of Clinical and Diagnostic Research: JCDR, 9(11), ZD16-ZD19. http://doi.org/10.7860/JCDR/2015/14273.6772

Moskovitz, M., Holan G., 2004 Pre-eruptive intracoronal radiolucent defect: a case of a nonprogressive lesion. Journal of Dentistry for Children 71(2), 175-178.

Neuville, R. 1951 Le Paléolithique et le Mésolithique du désert de Judée. Archives de l'Institut de Paléontologie Humaine Paris : Masson.

Ollat, D., Versier, G., Moyen, B., Lefort, G., 2008. Traitement de l'ostéochondrite disséquante chez l'adolescent. E-mémoires l'Académie Nationale de Chirurgie, 7, 60-63. 
Orhan, K., Arslan, A., Kocyigi,t D. 2006. Temporomandibular joint osteochondritis dissecans: case report. Oral Surgery, Oral Medicine, Oral Pathology, Oral Radiology, and Endodontology, 102, e41-e46.

Ortner, D.J. 2003. Identification of Pathological Conditions in Human Skeletal Remains, Academic Press, 645p. https://doi.org/10.1016/B978-0-12-528628-2.X5037-6

Rak ,Y. 1990. On the differences between two pelvises of Mousterian context from the Qafzeh and Kebara caves, Israel. American Journal of Physical Anthropology, 81, 323-332

Sarig, R., Slon, V., Abbas, J., May, H., Shpack, N., Vardimon, A.D., Hershkovitz, I., 2013 Malocclusion in Early Anatomically Modern Human: A Reflection on the Etiology of Modern Dental Misalignment. PLoS ONE 8(11), e80771. https://doi.org/10.1371/journal.pone.0080771

Sarrat, P., Cheynet, F., Chossegros, C., Orthlieb, J.D., Philip, E., Carrasset, S., Bayle, O., 1999. IRM de l'articulation temporo-mandibulaire (ATM) dysfonctionnelle. Journal de radiologie, $80,1543-54$

Savage, N.W., Gentner, M., Symons, A.L. 1998. Preeruptive intracoronal radiolucencies : review and report case. ASDC journal of dentistry for children. 65(1), 36-40

Schellhas, K.P., Wilkes, C.H., Fritts, H.M., Omlie, M.R., Lagrotteria, L.B. 1989. MR of ostéochondritis dissecans and avascular necrosis of the mandibular condyle. American Society of Neuroradiology, 152, 551-60.

Schuh, A., Dutailly, B., Coutinho Nogueira, D., Santos, F., Arensburg, B., Vandermeersch, B., Coqueugniot, H., Tillier A.-m. 2017. La mandibule de l'adulte Qafzeh 25 (Paléolithique moyen), Basse Galilée : reconstruction virtuelle 3D et analyse morphométrique. Paléorient, 43$1,49-59$

Schwarcz, H., Grün, R., Vandermeersch, B., Bar-Yosef, O., Valladas, H., Tchernov, E. 1988. ESR dates for the Hominid Burial site of Qafzeh in Israel. Journal of Human Evolution, 17, 733-737. https://doi.org/10.1016/0047-2484(88)90063-2

Sognnaes, R.F. 1956. Histologic Evidence of Developmental Lesions in Teeth originating from Paleolithic, Prehistoric, and Ancient Man. American Journal of Pathology, 32, 547-577

Spoor, C.F., Zonneveld, F.W., Macho, G.A. 1993. Linear measurements of cortical bone and dental enamel by computed tomography: applications and problems. Am J Phys Anthrop 91, $469-484$. 
Stafne, E.C. 1942. Bone cavities situated near the angle of the mandible. Journal of the American Dental Association, 29:1969-72

Tillier, A.-m., Arensburg, B., Rak, Y., Vandermeersch, B., 1995. Middle Palaeolithic Dental Caries: New Evidence from Kebara (Mount Carmel, Israel). Journal of Human Evolution, 29, 189-192.

Tillier, A.-m., 1999. Les enfants moustériens de Qafzeh. Interprétation phylogénétique et paléoauxologique. Paris: Cahiers de Paléoanthropologie, CNRS Editions. 239 p.

Tillier, A., Arensburg, B., Duday, H. and Vandermeersch, B. 2001, Brief communication: An early case of hydrocephalus: The Middle Paleolithic Qafzeh 12 child (Israel). Am. J. Phys. Anthropol., $\quad 114, \quad$ 166-170. $\quad$ DOI:10.1002/1096-8644(200102)114:2<166::AIDAJPA1017>3.0.CO;2-3

Tillier, A.-m., Duday, H., Arensburg, B., Vandermeersch B., 2004. Dental Pathology, Stressful Events, and Disease in Levantine Early Anatomically Modern Humans: Evidence from Qafzeh. In: Goren-Inbar N. and Speth J.D. (eds.), Human Paleoecology in the Levantine Corridor, 135148. Oxbow Books Oxford.

Tillier, A.-m. 2006. Les plus anciens Homo sapiens (sapiens). Perspectives biologique, chronologique et taxinomique. Naissance de la pensée symbolique et du langage. Numéro spécial à l'occasion du XVe Congrès de l'UISPP, Unesco, Paris., Diogène, 214, 132-146

Tillier, A.-m. 2007. Dental development and Pathology from Middle Palaeolithic Levant. Evidence from Kebara and Qafzeh hominids. In: Faerman, M., Kolska Horvitz, L., Kahana, T., Zilberman, U., (eds.), Faces from the Past: Diachronic patterns in the Biology and Health Status of Human Populations in the Eastern Mediterranean. Festschrift in Honour of Patricia Smith, 36-43. Oxford

Tillier, A.-m. 2014. New Middle Palaeolithic hominin Dental Remains from Qafzeh (Israel). Paléorient 40-1, 13-24

Trinkaus, E., Pinilla, B. (2009) Dental Caries in the Qafzeh 3 Middle Paleolithic Modern Human. Paléorient, 36-1, 69-76

Uldin, T. (2017) Virtual anthropology - a brief review of the literature and history of computed tomography, Forensic Sciences Research, 2:4, 165-173, DOI: $10.1080 / 20961790.2017 .1369621$ 
Valladas, H., Reyss, J.L., Joron, J.L., Valladas, G., Bar Yosef, O., Vandermeersch, B., 1988 Thermoluminescence dating of Mousterian "Proto-cro-magnon" remains from Israel and the origin of Modern man. Nature 331, 614-616.

Vandermeersch B., 1969. Les nouveaux squelettes moustériens découverts à Qafzeh et leur signification. C. R. Acad. Sc. Paris. 268, D, 2562-2565

Vandermeersch, B. 1981. Les hommes fossiles de Qafzeh, Cahiers de Paléoanthropologie, CNRS Editions, Paris, 319 p.

Vandermeersch, B. 2007. Qafzeh, histoire des découvertes, Bulletin du Centre de recherche français à Jérusalem, 18, 8-19

Weber, G.W., Bookstein, F.L. 2011. Virtual anthropology - a guide to a new interdisciplinary field. Verlag: Springer, 423p. 


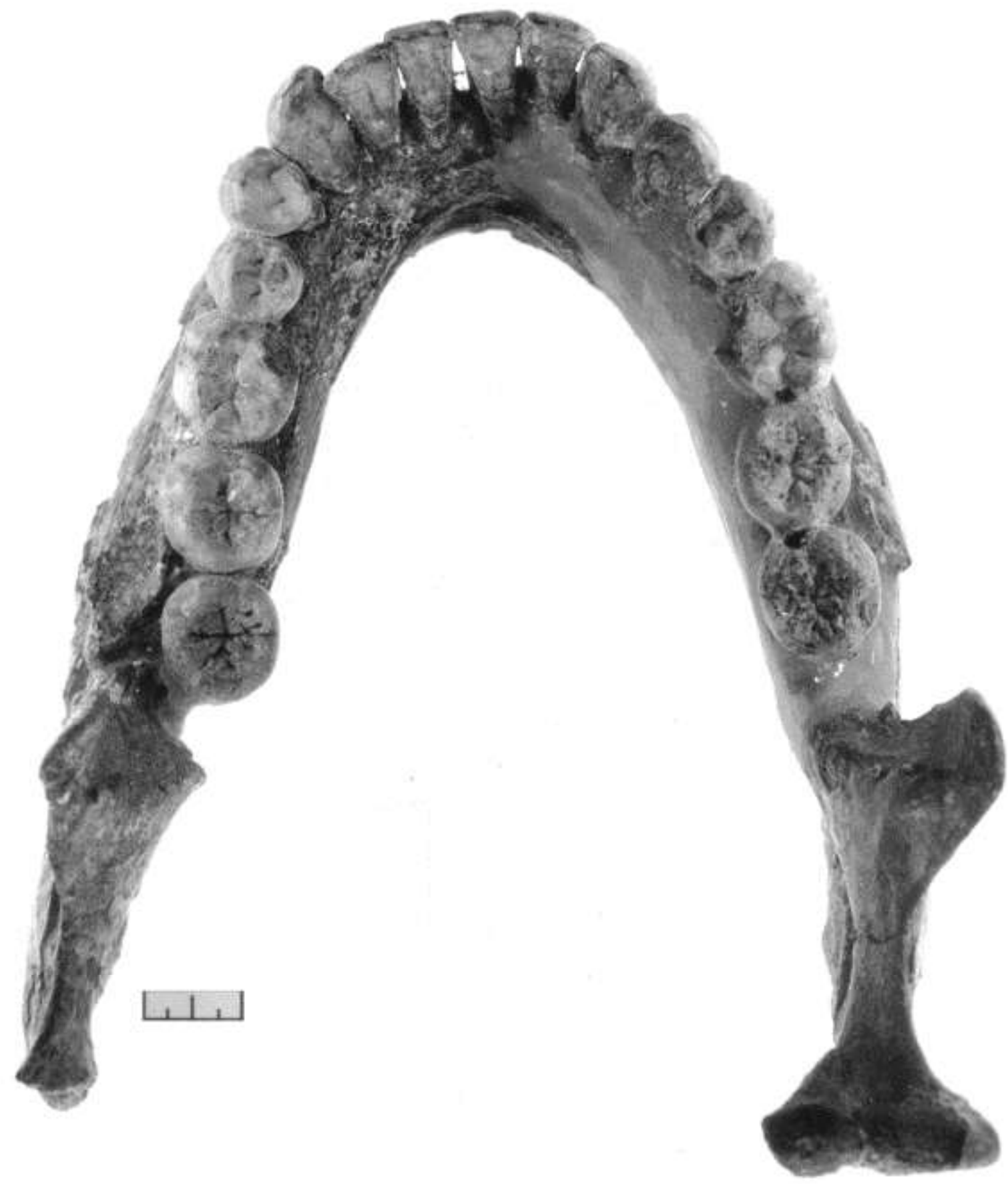




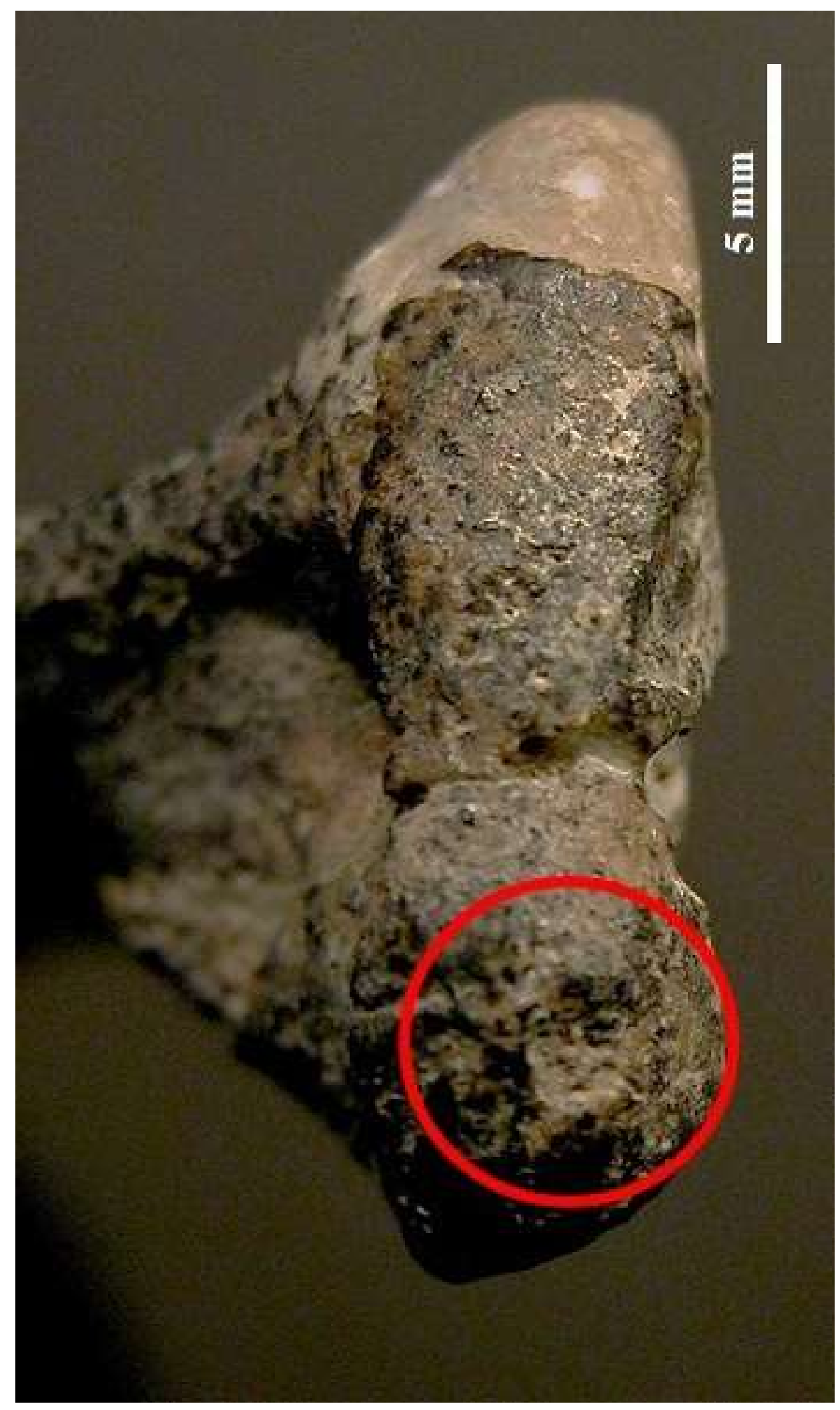




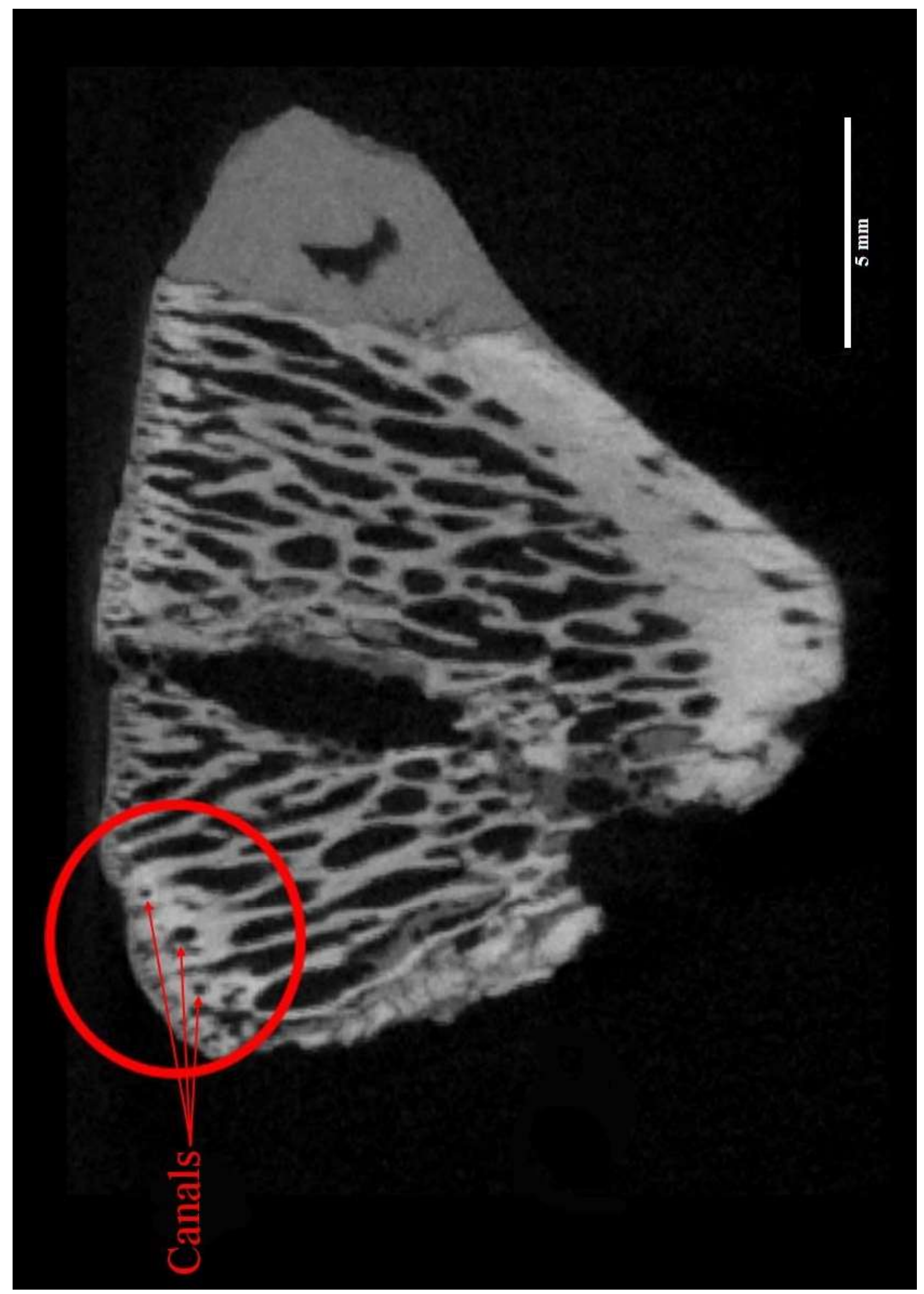




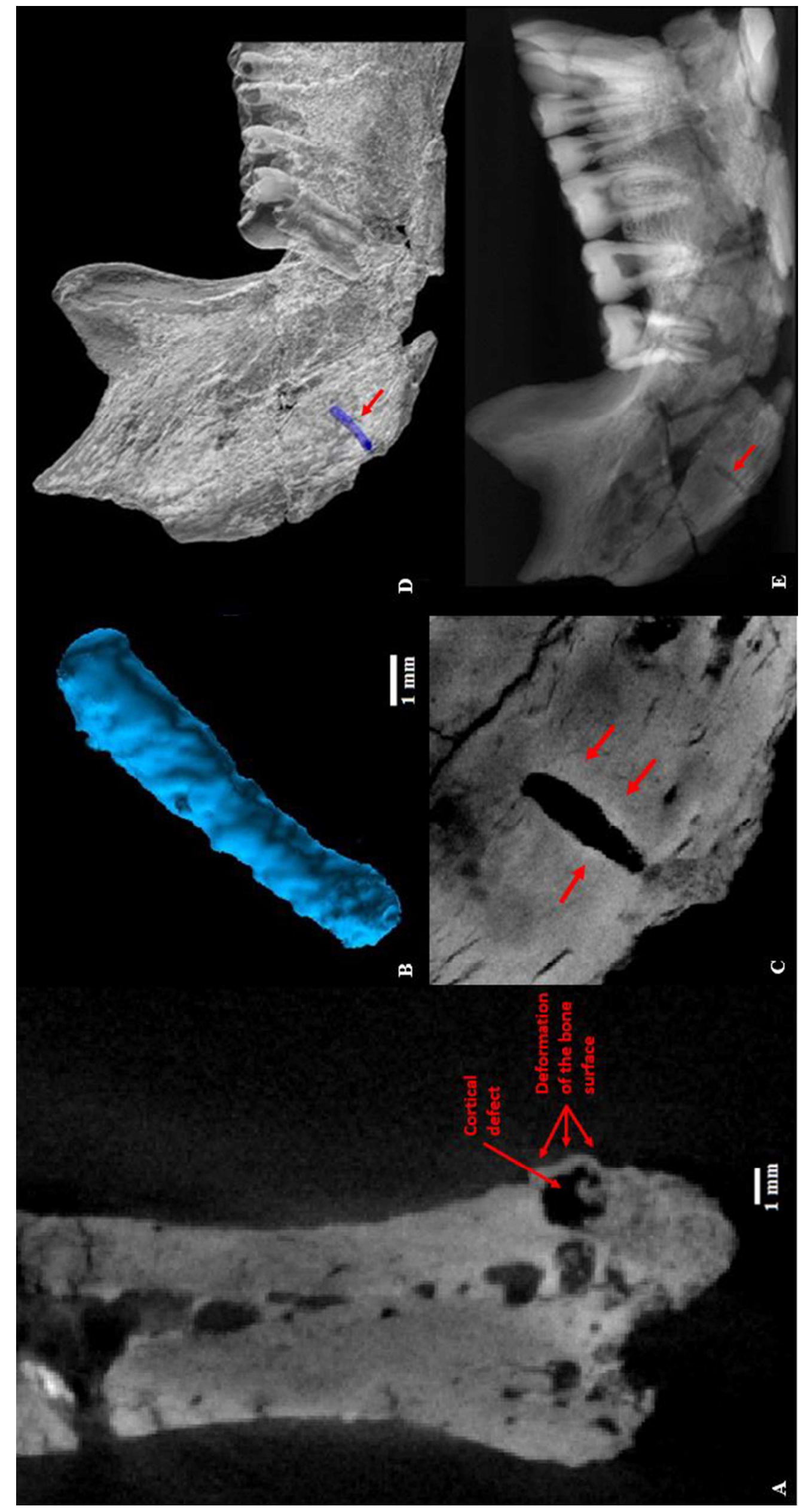




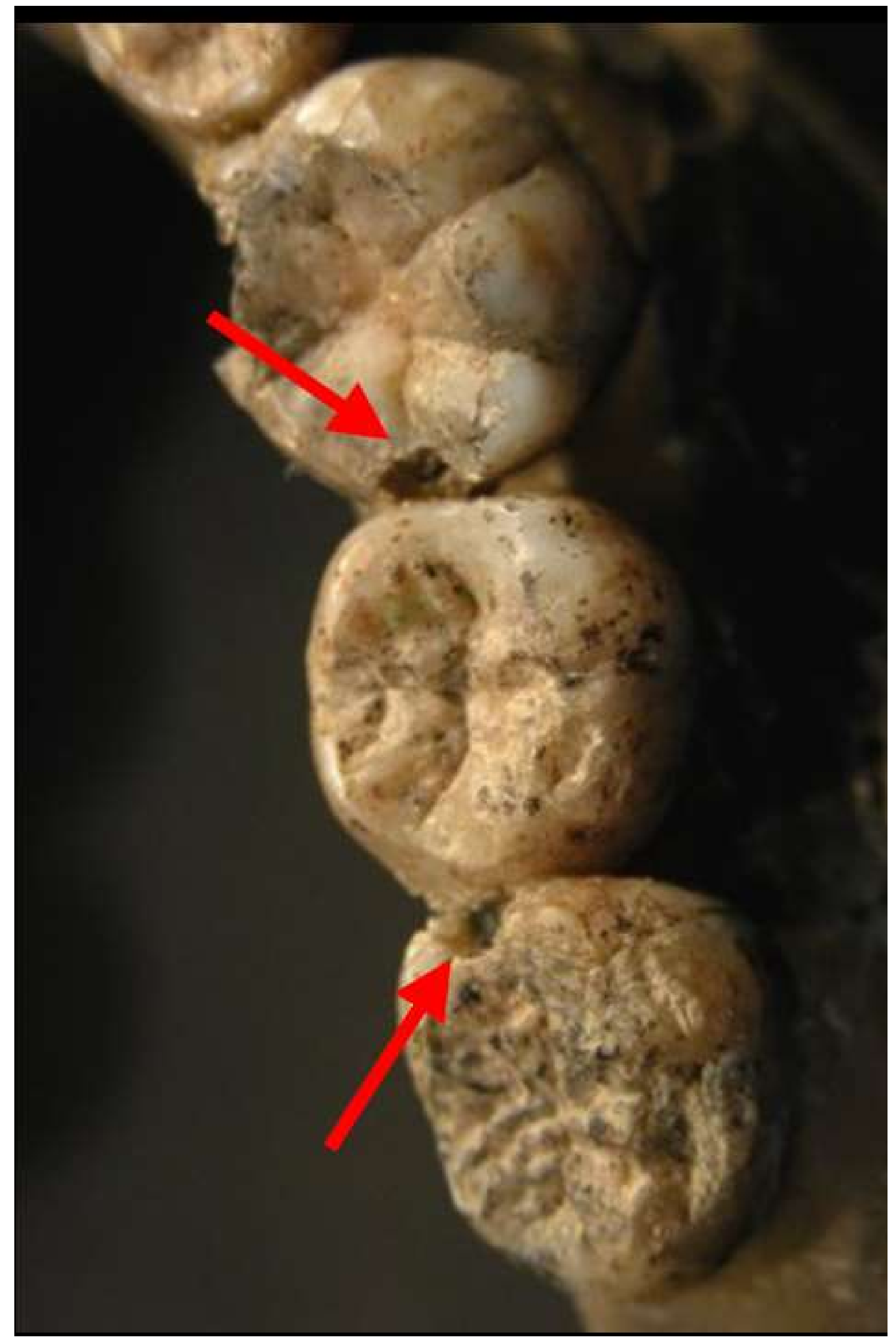




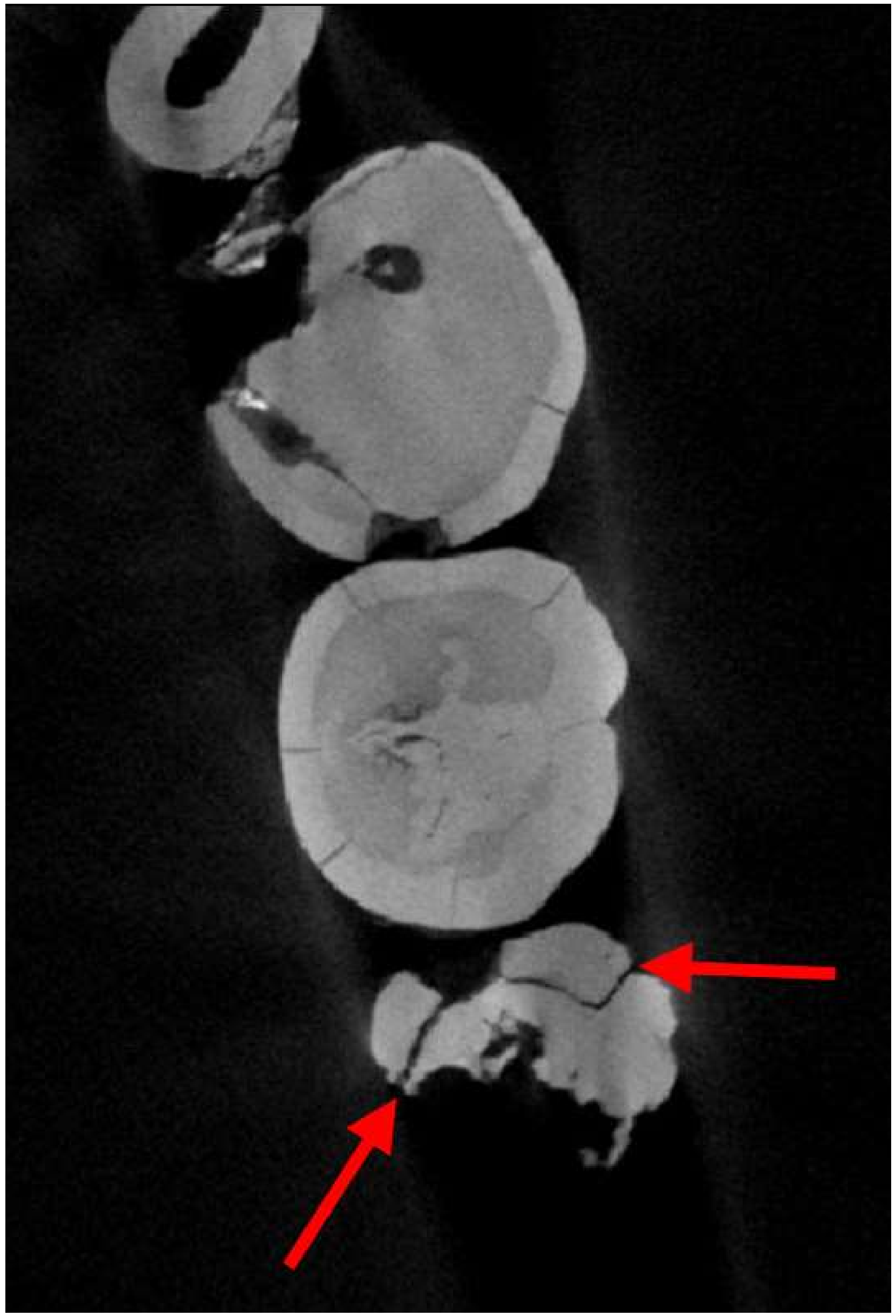




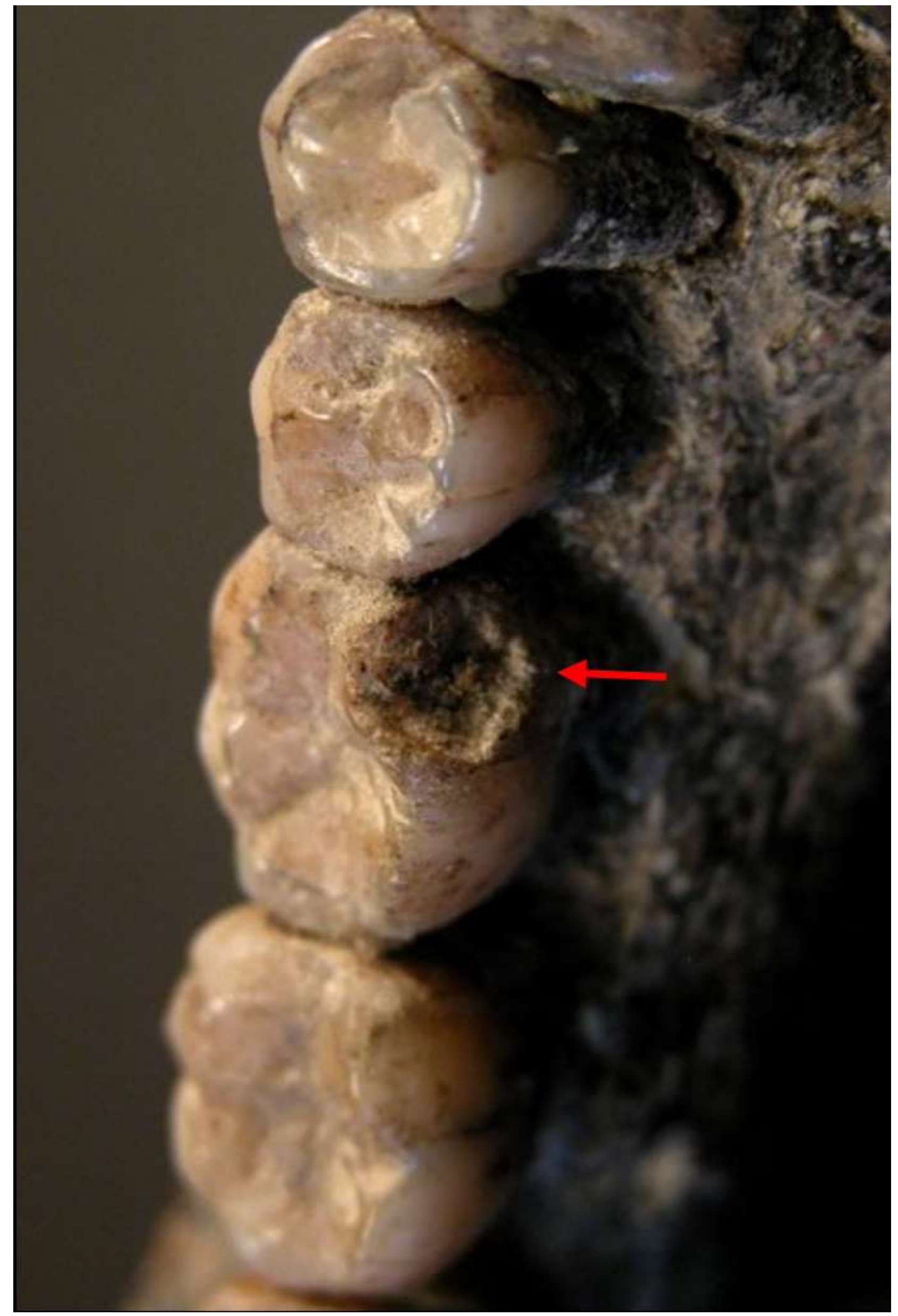




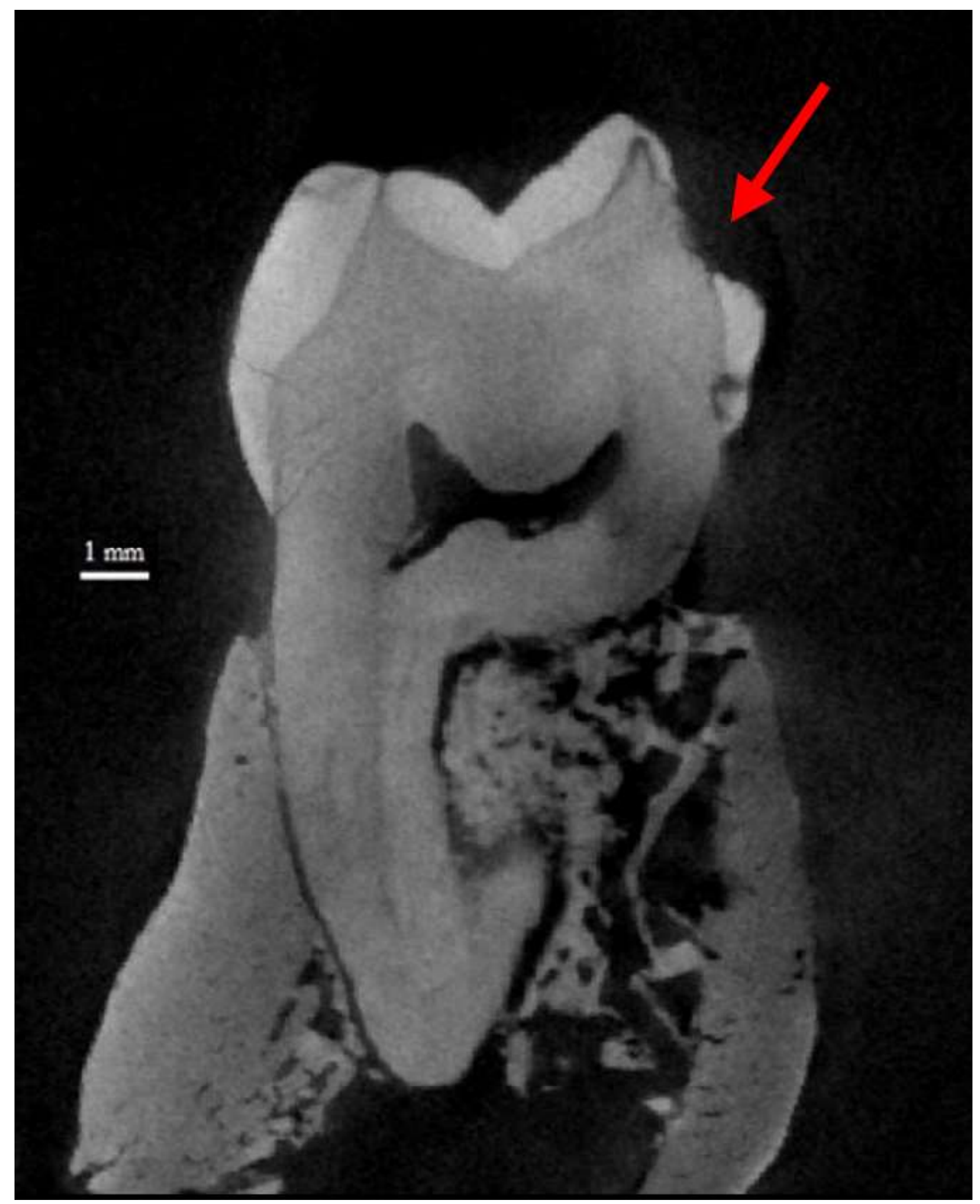




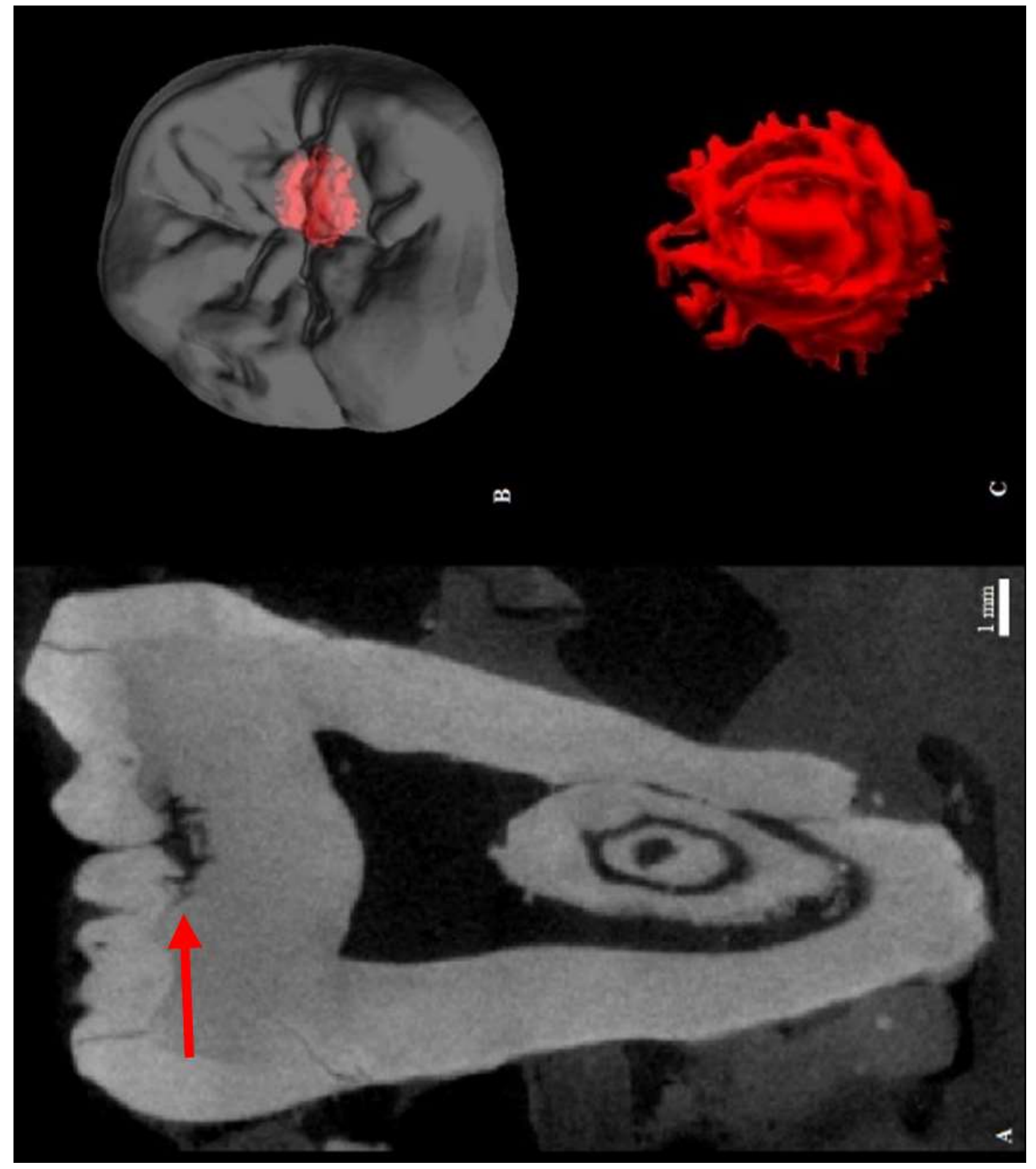




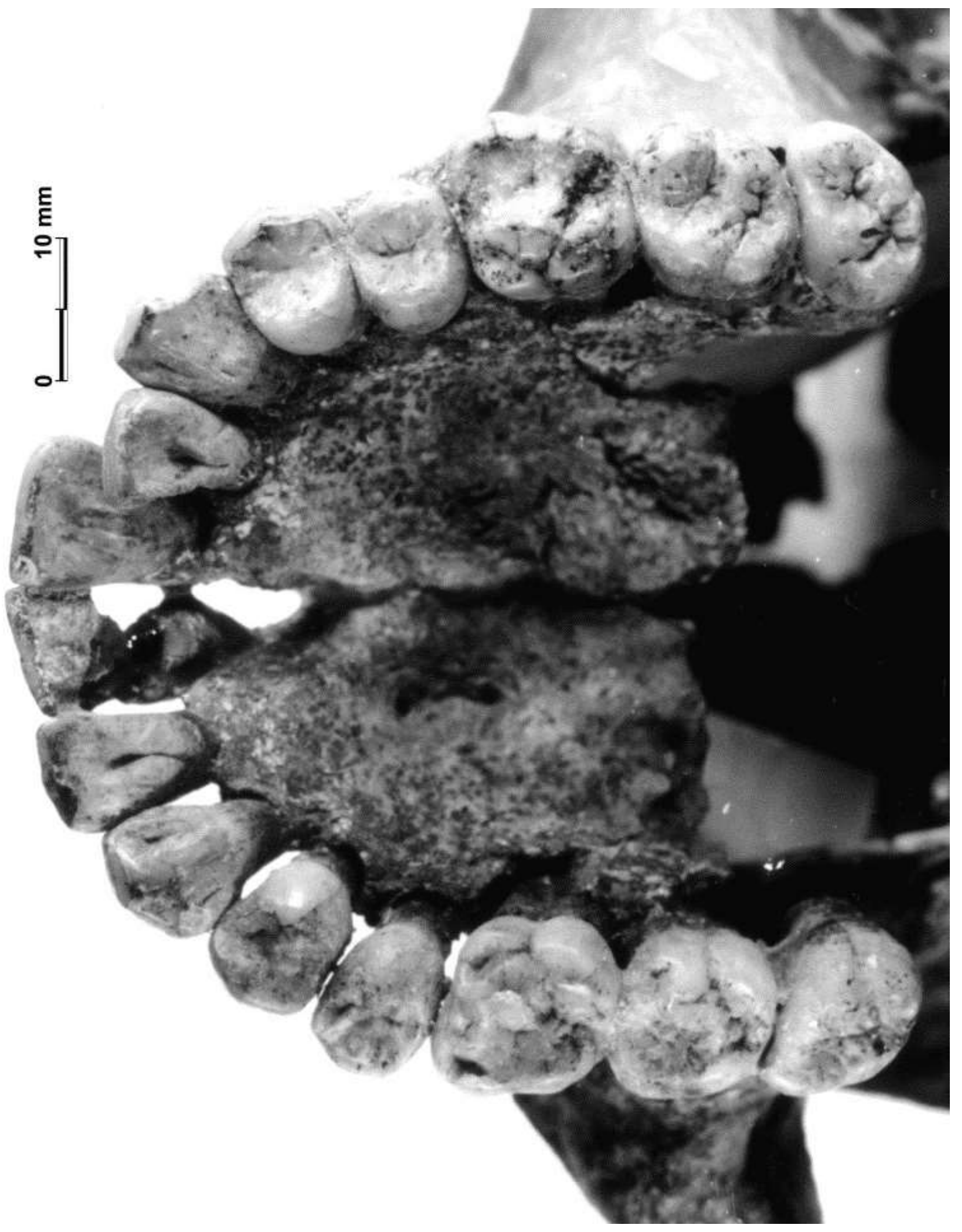

